\title{
Study on Ultrasonic-Microwave Synergistic Extraction Process of Tengjiao(Zanthoxylum schinifolium) Oil
}

\author{
Dong $\mathrm{Li}^{1, \mathrm{a}^{*}}$,Jie Zou ${ }^{1, \mathrm{~b}}$, Yue Yuan ${ }^{1, \mathrm{c}}$, Jianjun Guo ${ }^{1, \mathrm{~d}}$, Wen $\mathrm{Xu}{ }^{1, \mathrm{e}}$, \\ Qin Yuan ${ }^{1, f}$, Longling Chen ${ }^{1, g}$, \\ ${ }^{1}$ Dept .of Bioengineering, Sichuan University of Science and Engineering ,Zigong Sichuan, \\ China ,643000

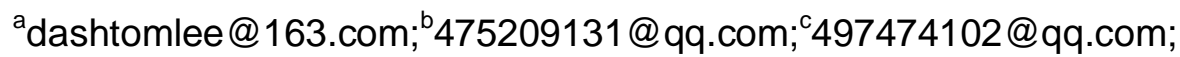

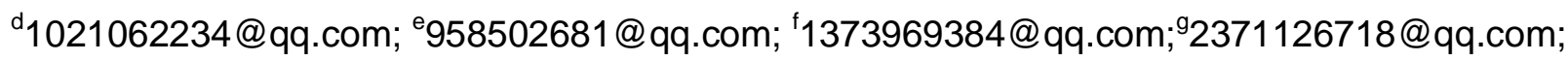 \\ *dashtomlee@163.com
}

Keywords: Zanthoxylum schinifolium et Zucc; Ultrasonic-Microwave Synergistic; Extraction Process

Abstract. The ultrasonic-microwave synergistic extraction process parameter of Tengjiao (Zanthoxylum schinifolium) oil, such as time, temperature, ratio of solid to liquid, microwave power and ultrasonic power, have been studied by orthogonal experiments. The results indicate that, using colza oil as the extraction medium, the best processes were $7 \mathrm{~min}, 110^{\circ} \mathrm{C}$, ratio of solid to liquid $1: 25$, microwave power $400 \mathrm{~W}$ and ultrasonic power $800 \mathrm{~W}$.

\section{Introduction}

Tengjiao,a kind of Zanthoxylum schinifolium et Zucc, has been used of hundreds years in southwest China[1].The fresh fruit which has a special aroma is used as traditional Chinese condiment for cooking[2].Since hundreds of years ago, the local residents produced the Tengjiao oil, using hot plant oil, such as colza oil, extract the effective components from the fresh fruit, to preserve the special aroma[3]. But the oil which produced by traditional technology, only contain a little of special aroma. Ultrasonic-microwave synergistic extraction which was a kind of new technology, not only extract efficiently, but also can improve the quality of oil, save materials, increase the amount of extracted oil, and save energy[4]. This article have studied on the ultrasonic-microwave synergistic extraction process parameter of Tengjiao oil, such as time, temperature, ratio of solid to liquid, microwave power and ultrasonic power by orthogonal experiments. The result will provide a theoretical basis for the development and produce of Tengjiao oil.

\section{Materials and methods}

Materials. Tengjiao were provided by the Xingjiang Company of Hongya.

Instruments and reagents. SL-1200 ultrasonic combination microwave reaction system:made by Nanjing downstream Instrument Co., Ltd.,FA1104 electron balance: made by Todo Mettler Instrument (Shanghai) Co., Ltd., UV1000 UV-visible spectrophotometer: made by Shanghai Tianmei Scientific Instruments Co., Ltd., HWS-12 Electric heated water bath:made by Shanghai Yiheng Scientific Instruments Co., Ltd., TDL-S-A centrifuge made by Shanghai Anting Scientific Instruments Co., Ltd., dry methanol (AR).

Methods. The Tengjiao have been triturated into powder, and sieved by the 26 mesh.50g of colza oil and different amount of Tengjiao powder were placed into $100 \mathrm{ml}$ special glass extract instrument, ultrasonic-microwave extract different time and power, orthogonal experiments have processed, in order to select the optimum extraction conditions. $0.1 \mathrm{ml}$ Tengjiao oil dissolve into dry methanol and constant volume to $10 \mathrm{ml}$, bath $40^{\circ} \mathrm{C}$ and $4 \mathrm{~h}$, and centrifuged for $15 \mathrm{~min}$ for $4500 \mathrm{r} / \mathrm{min}$, and the 
supernatant absorbance value of 254nm were detected [5,6].The GC-MS analysis just as Qin \& Luo's methods[7,8].

\section{Results and discussion}

Preliminary experiment.It was found that the Tengjiao oil ultrasonic extraction optimum conditions was $13 \mathrm{~min}, 1000 \mathrm{~W}$, and ratio of solid to liquid 1:25, and the the Tengjiao oil microwave extraction optimum conditions was $10 \mathrm{~min}, 180^{\circ} \mathrm{C}, 600 \mathrm{~W}$, and ratio of solid to liquid 1:25.(The results has been published on other journals.)

Orthogonal test. On the basis of preliminary experiment, five factors and four levels orthogonal experiment to examine the effect of time, temperature, ratio of solid to liquid, microwave power and ultrasonic power. The absorbance value are used as indicators to determine the optimum level of ultrasonic-microwave synergistic extraction. Orthogonal test results are shown in Table 1.

Table.1 Orthogonal test results and analysis

\begin{tabular}{ccccccc}
\hline No. & Time $(\mathrm{min})$ & $\begin{array}{c}\text { Temperature } \\
\left({ }^{\circ} \mathrm{C}\right)\end{array}$ & $\begin{array}{c}\text { Ratio of solid } \\
\text { to liquid }\end{array}$ & $\begin{array}{c}\text { Microwave } \\
\text { Power }(W)\end{array}$ & $\begin{array}{c}\text { Ultrasonic } \\
\text { power }(W)\end{array}$ & $\begin{array}{c}\text { Absorbance } \\
\text { values }\end{array}$ \\
\hline 1 & $1(7 \mathrm{~min})$ & $1\left(90^{\circ} \mathrm{C}\right)$ & $1(1: 25)$ & $1(300 \mathrm{~W})$ & $1(600 \mathrm{~W})$ & 2.911 \\
2 & 1 & $2\left(100^{\circ} \mathrm{C}\right)$ & $2(1: 30)$ & $2(400 \mathrm{~W})$ & $2(800 \mathrm{~W})$ & 2.874 \\
3 & 1 & $3\left(110^{\circ} \mathrm{C}\right)$ & $3(1: 35)$ & $3(500 \mathrm{~W})$ & $3(1000 \mathrm{~W})$ & 2.755 \\
4 & 1 & $4\left(120^{\circ} \mathrm{C}\right)$ & $4(1: 40)$ & $4(600 \mathrm{~W})$ & $4(1200 \mathrm{~W})$ & 2.326 \\
5 & $2(10 \min )$ & 1 & 2 & 3 & 4 & 2.550 \\
6 & 2 & 2 & 1 & 4 & 3 & 2.932 \\
7 & 2 & 3 & 4 & 1 & 2 & 2.469 \\
8 & 2 & 4 & 3 & 2 & 1 & 2.716 \\
9 & $3(13 \min )$ & 1 & 3 & 4 & 2 & 2.726 \\
10 & 3 & 2 & 4 & 3 & 1 & 2.214 \\
11 & 3 & 3 & 1 & 2 & 4 & 2.884 \\
12 & 3 & 4 & 2 & 1 & 3 & 2.659 \\
13 & $4(16 \mathrm{~min})$ & 1 & 4 & 2 & 3 & 2.264 \\
14 & 4 & 2 & 3 & 1 & 4 & 2.472 \\
15 & 4 & 3 & 2 & 4 & 1 & 2.635 \\
16 & 4 & 4 & 1 & 3 & 2 & 2.856 \\
$\mathrm{~K} 1$ & 2.716 & 2.613 & 2.896 & 2.628 & 2.619 & - \\
$\mathrm{K} 2$ & 2.667 & 2.623 & 2.679 & 2.684 & 2.731 & - \\
$\mathrm{K} 3$ & 2.621 & 2.686 & 2.667 & 2.594 & 2.652 & - \\
$\mathrm{K} 4$ & 2.557 & 2.639 & 2.318 & 2.655 & 2.558 & - \\
$\mathrm{R}$ & 0.159 & 0.073 & 0.578 & 0.090 & 0.173 & - \\
\hline
\end{tabular}

According to Table 1, the most important effect factor was the ratio of solid to liquid, ultrasonic power was the second important effect factor, time was the third, microwave power was the fourth and the effect of temperature was the minimum. It was found that the Tengjiao oil ultrasonic-microwave synergistic extraction optimum conditions was $\mathrm{A}_{1} \mathrm{~B}_{3} \mathrm{C}_{1} \mathrm{D}_{2} \mathrm{E}_{2}$, which was $7 \mathrm{~min}$, $110^{\circ} \mathrm{C}$, ratio of solid to liquid $1: 25$, microwave power $400 \mathrm{~W}$ and ultrasonic power $800 \mathrm{~W}$.

Verification tests. The optimum conditions $\mathrm{A}_{1} \mathrm{~B}_{3} \mathrm{C}_{1} \mathrm{D}_{2} \mathrm{E}_{2}$ was not exist in the orthogonal experiment. $50 \mathrm{~g}$ of colza oil were placed in the reaction vessel, $7 \mathrm{~min}, 110^{\circ} \mathrm{C}$, ratio of solid to liquid 1:25, 
microwave power $400 \mathrm{~W}$ and ultrasonic power $800 \mathrm{~W}$, the absorbance value was measured. The result showed that absorbance value of $\mathrm{A}_{1} \mathrm{~B}_{3} \mathrm{C}_{1} \mathrm{D}_{2} \mathrm{E}_{2}$ was 2.992, which was the highest value of all.

GC-MS analysis. The Tengjiao oil which made by ultrasonic-microwave synergistic extraction methods, was analyzed by GC-MS. It was found that the volatile components mainly consist of linalool, dextral limonene, myrcene, elemene and caryophyllene. Compared with the Tengjiao oil which produced by traditional technology, effective component species did not change, but the content and the ratio of effective component are differently. GC-MS results are shown in Table 2 and Figure 1.

Table.2 Tengjiao oil composition and relative content

\begin{tabular}{|c|c|c|c|c|}
\hline NO. & Time(min) & name & $\begin{array}{l}\text { molecular } \\
\text { formula }\end{array}$ & $\begin{array}{l}\text { relative } \\
\text { content } \\
(\%)\end{array}$ \\
\hline 6 & 8.078 & 3-Thujene & $\mathrm{C}_{10} \mathrm{H}_{16}$ & 1.509 \\
\hline 7 & 10.441 & Sabinene & $\mathrm{C}_{10} \mathrm{H}_{16}$ & 8.421 \\
\hline 8 & 11.532 & Myrcene & $\mathrm{C}_{10} \mathrm{H}_{16}$ & 2.737 \\
\hline 9 & 12.275 & Terpinolene & $\mathrm{C}_{10} \mathrm{H}_{16}$ & 0.456 \\
\hline 10 & 12.92 & $\begin{array}{l}\text { Cyclohexene,1-methyl-4-(1-methylet } \\
\text { nyl)-,(4R)- }\end{array}$ & $\mathrm{C}_{10} \mathrm{H}_{16}$ & 20.702 \\
\hline 11 & 13.278 & $\begin{array}{l}\text { 3-methylene-6-(1-methylethyl)-Cycl } \\
\text { ohexene }\end{array}$ & $\mathrm{C}_{10} \mathrm{H}_{16}$ & 1.193 \\
\hline 12 & 13.388 & Cineole & $\mathrm{C}_{10} \mathrm{H}_{16}$ & 1.158 \\
\hline 13 & 14.462 & g-Terpinene & $\mathrm{C}_{10} \mathrm{H}_{16}$ & 1.789 \\
\hline 14 & 17.084 & 1,3-Dimethylcyclopentane & $\mathrm{C}_{7} \mathrm{H}_{14}$ & 0.807 \\
\hline 15 & 19.211 & 1-Nonanal & $\mathrm{C}_{9} \mathrm{H}_{18} \mathrm{O}$ & 1.544 \\
\hline 16 & 22.29 & Furan, 2-propyl- & $\mathrm{C}_{7} \mathrm{H}_{10} \mathrm{O}$ & 2.105 \\
\hline 17 & 23.529 & Linalool & $\mathrm{C}_{10} \mathrm{H}_{18} \mathrm{O}$ & 33.158 \\
\hline 18 & 24.703 & (-)-g-Cadinene & & 1.053 \\
\hline 19 & 24.978 & $\beta$-Elemene & $\mathrm{C}_{15} \mathrm{H}_{24}$ & 2.667 \\
\hline 20 & 25.358 & 1-Caryophyllene & $\mathrm{C}_{15} \mathrm{H}_{24}$ & 2.070 \\
\hline 21 & 26.355 & 2-Cyclohexen-1-ol & $\mathrm{C}_{6} \mathrm{H}_{10} \mathrm{O}$ & 1.298 \\
\hline 22 & 28.977 & $\begin{array}{l}\text { Naphthalene, } 1,2,3,4,4 \mathrm{a}, 5,6,8 \mathrm{a}-\text { octahy } \\
\text { dro-4a,8-dimethyl-2-(1-methyletheny } \\
\text { 1)-, (2R,4aR,8aR)- }\end{array}$ & $\mathrm{C}_{15} \mathrm{H}_{24}$ & 0.877 \\
\hline 23 & 29.451 & - & - & 1.123 \\
\hline 24 & 31.148 & trans,trans-2,4-Decadien-1-al & $\mathrm{C}_{10} \mathrm{H}_{16} \mathrm{O}$ & 2.702 \\
\hline
\end{tabular}

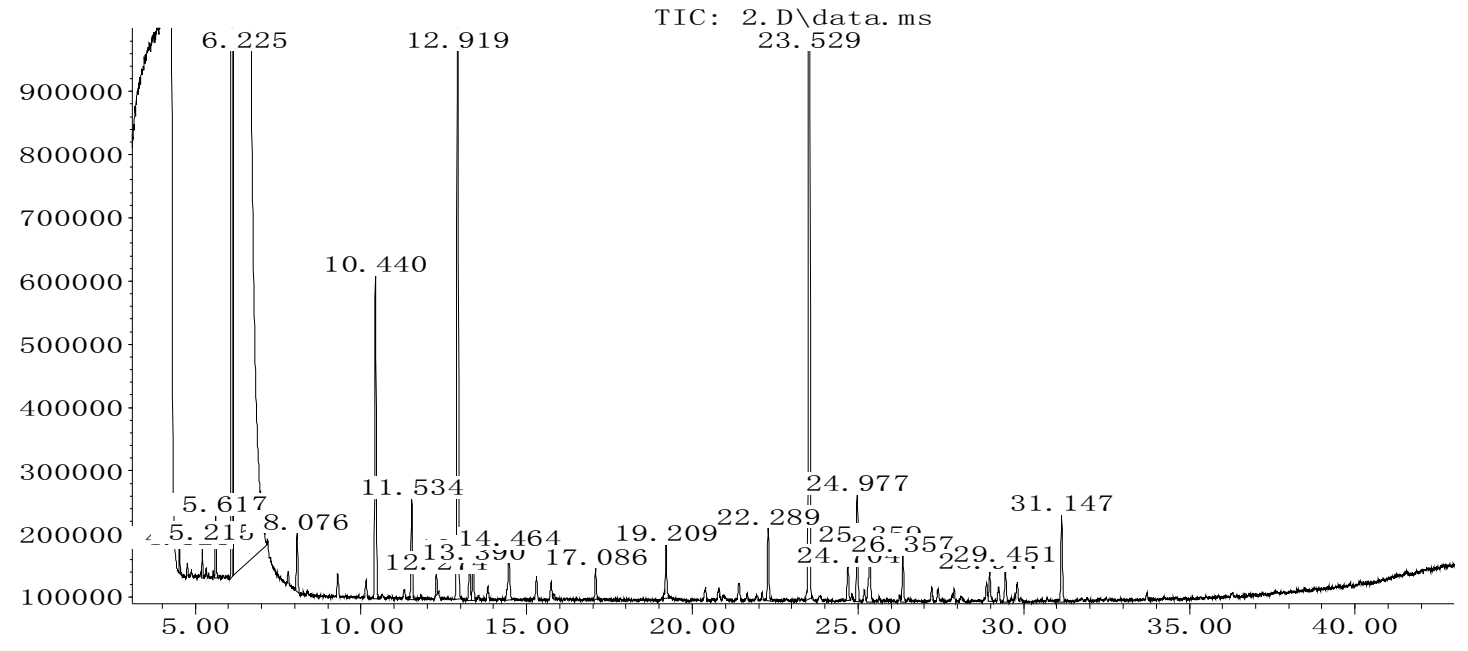

Figure 1 Tengjiao oil GC-MS analysis 


\section{Conclusions}

Ultrasonic-microwave synergistic extraction of Tengjiao oil compared with traditional processes can greatly save time and improve product quality. The results of orthogonal experiment were shown that the optimum levels of ultrasonic-microwave synergistic extraction were $7 \mathrm{~min}, 110^{\circ} \mathrm{C}$, ratio of solid to liquid 1:25, microwave power $400 \mathrm{~W}$ and ultrasonic power $800 \mathrm{~W}$, which means less time, lower temperature, microwave power and ultrasonic power than ultrasonic extraction and microwave extraction. The result of this experiment means ultrasonic-microwave synergistic extraction technology shows the advantage only in the laboratory, and could not use in industrial applications directly. The industrial applications of ultrasonic-microwave synergistic extraction are one of the problems of the food industry in the future and need further study.

\section{Acknowledgements}

This work was financially supported by Sichuan University of Science and Engineering Funding (2014RC09), Sichuan University of Science and Engineering Students Innovation Training Project Funding (CX20141410) and Sichuan Education Department Project Funding (15ZB0216).

\section{References}

[1] Zhengcai Li. Science and Technology of Sichuan Agriculture,2004(9):15-16. (In Chinese)

[2] Zhifeng Zhao,Xu Gong,Zhe Qin,et al.China Condiment,2008,(1):84-87. (In Chinese)

[3] Shaohei Jin.Nong Chan Pin Jia Gong,2007,(11):38-40. (In Chinese)

[4] Shengdan Yang, Dayou Fu.Guangdong Chemical Industry, 2010,37(2):120-122.(In Chinese)

[5] Chenmei Fu.China Food Additives, 2003,(06):100-102.(In Chinese)

[6] Xiong Liu. Food and Fermentation Industry, 2004,(09):112-116.(In Chinese)

[7] Jun Qin, Tong Chen, Qing Lu. Journal of Guizhou University of Technology. 2001(6):4-6. (In Chinese)

[8] Kai Luo, Lin Zhu, Jianquan Kan et al. Food and Fermentation Industries. 2012(5): 209-212(In Chinese) 